
de colheita. Horticultura Brasileira 25: 371-374.

\title{
Fisiologia e produção de cultivares de batata-doce em função da época de colheita
}

\author{
Roberto Cleiton Fernandes de Queiroga'; Maria Auxiliadora dos Santos²; Márcio André de Menezes²; \\ Clemens Paula Gomes Vieira²; Maria da Conceição Silva² \\ ${ }^{1}$ UFV, Depto. Fitotecnia, 36571-000 Viçosa-MG; ' ${ }^{2}$ FERSA, Depto. Ciências Vegetais, C. Postal 137, 59625-900 Mossoró-RN; \\ robertocleiton@hotmail.com
}

\section{RESUMO}

O experimento foi realizado em campo com objetivo de avaliar características fisiológicas e de produção das cultivares de batatadoce ESAM 1, 2 e 3, colhidas aos 105, 130 e 155 dias após o plantio (DAP). Os tratamentos foram dispostos em blocos completos casualizados, em esquema fatorial 3 x 3, com quatro repetições. Entre as variáveis que integram o aparelho assimilatório das cultivares, somente o tamanho da folha diferiu significativamente. Considerando as épocas estudadas, as cultivares apresentaram aos 155 DAP, ou seja, 25 dias além do ciclo recomendado, menor tamanho e número de folhas e mais baixa razão de área foliar, porém foram mais eficientes quanto à translocação de fotoassimilados para as raízes. Assim, aumentaram significativamente o número de raízes comerciais por planta e, conseqüentemente, a produtividade de raízes comerciais e a produtividade total de raízes.

Palavras-chave: Ipomoea batatas, índice de colheita, idade da planta, características fisiológicas.

\section{ABSTRACT}

Physiology and yield of sweet-potato cultivars depending on harvesting time

A field experiment was carried out in Mossoró, Rio Grande do Norte State, Brazil, to evaluate the physiological characteristics and yield of sweet-potato cultivars ESAM 1, 2, and 3, harvested at 105, 130 , and 155 days after planting date. The experiment was a $3 \times 3$ factorial in a randomized complete blocks design with four replications. Among the variables that compose the assimilatory apparatus of the cultivars, only leaf size was significantly different. The cultivars harvested at 155 days after planting date (i.e., 25 days after the recommended cycle) presented fever and smaller leaves and showed smaller leaf area ratio. However, they performed more efficiently in photosynthate translocation to storage roots, which increased significantly the number of marketable roots per plant and, consequently, both marketable and total root yields.

Keywords: Ipomoea batatas, harvest index, plant age, physiological characteristics.

\section{(Recebido para publicação em 15 de janeiro de 2006; aceito em 5 de julho de 2007)}

A batata-doce [(Ipomoea batatas ( $L$.) Lam)] é uma hortaliça tuberosa cultivada em todo território brasileiro, sendo bastante rústica, de ampla adaptação, tolerante à seca e de fácil cultivo (Silva \& Lopes, 1995). De acordo com dados do IBGE (2005), em 2003 no Brasil foram produzidas 533.165 t, com área colhida de 46.351 ha, destacando-se o estado do Rio Grande do Sul com aproximadamente 31\% da área plantada. No Nordeste, os estados da Paraíba, Sergipe, Pernambuco, Rio Grande do Norte, Bahia e Alagoas concentram 40\% da área plantada no país. Nessa região, a batata-doce é uma cultura bastante difundida e cultivada, consumida pelos produtores e o excedente é comercializado em mercados locais ou nos estados vizinhos (Pereira et al., 2003). As raízes constituem a fonte mais popular de energia, minerais e vitaminas, principalmente para os consumidores de baixa renda. No Rio Grande do Norte, as cultivares ESAM 1, 2 e 3, selecionadas em Mossoró-RN, são recomendadas devido a apresentarem boa produtividade de raízes (30 a $35 \mathrm{t} \mathrm{ha}^{-1}$ ), resistência a pragas e ciclo produtivo relativamente curto, variando entre 110 a 130 dias (Murilo et al., 1990). As raízes dessas cultivares são bem aceitas pelo mercado regional, que não é tão exigente quanto à forma, tamanho e colorações da película e polpa das raízes. Porém, são poucos ou quase inexistentes os estudos sobre as alterações fisiológicas e agronômicas destas cultivares resultantes de diferentes manejos ou práticas culturais.

As alterações no crescimento das plantas são determinadas a partir de caracteres fisiológicos como massa seca das plantas e de suas partes (raízes, caules, folhas) e área foliar (Richards, 1969 citado por Menezes et al., 2001), os quais permitem a obtenção de índices fisiológicos. Tais caracteres e índices, que podem ser avaliados durante o ciclo da cultura ou mesmo instantanea- mente, sofrem a interferência de fatores intrínsecos e extrínsecos à planta (Larcher, 1995), justificando as variações entre cultivares, com a idade da planta na colheita, e devido ao ambiente e às práticas culturais (Figueiredo, 1993).

Sabe-se que durante o crescimento anual da planta de batata-doce são identificadas três fases fisiológicas: a primeira em que predomina o desenvolvimento da parte aérea, embora aí sejam formadas as raízes absorventes e as aptas à tuberização, a segunda em que ocorre os crescimentos radical (tuberização) e vegetativo e a terceira em que prevalece a tuberização. Em um dos estudos realizados por Figueiredo (1993) com duas cultivares, visualizase bem essas fases através da sigmóide de crescimento. Ou seja, a produção de raízes tuberosas deverá ser máxima e qualitativamente melhor (matéria seca e carboidratos) quando as plantas atingirem o patamar sigmoidal. Assim, a de- 
terminação da época de colheita tem grande influência na produção vegetativa, na qualidade, produtividade de raízes e produção de fitomassa, sendo que seu manejo permite adequar a oferta à demanda. Além disso, a melhor época de colheita depende da cultivar, das condições ambientais (Smith \& Mantengo, 1995) e da demanda e preço do mercado, variando de acordo com a destinação do produto. Segundo Resende (2000), para mesa, a batatadoce pode ser colhida tão logo atinja o tamanho ideal de comercialização que varia entre 151 a $800 \mathrm{~g}$ em mercados menos exigentes, o que geralmente ocorre dos 100 aos 110 DAP para as cultivares precoces e, para a indústria pode ser colhida mais tarde, aos 180 DAP. Neste caso, para indústria, as batatas ficam maiores, com peso superando 800 g, influenciando na qualidade das raízes, tais como, porcentagens de matéria seca e de carboidratos, que geralmente são mais elevadas (Silva \& Lopes, 1995).

Poucos trabalhos têm sido realizados para avaliar a interferência da época de colheita sobre a qualidade e a produtividade de raízes de batata-doce. Doze clones foram avaliados por Peixoto et al. (1989) e colhidos aos 152 DAP, observando-se variações na produtividade de 16,7 a 27,0 t ha-1 de raízes, sendo a cultivar Brazlândia Branca a mais produtiva (27,0 t ha-1), seguida pela 'Princesa' (26,6 t ha-1), 'Brazlândia Rosada’ (25,8 t ha-1) e ‘Coquinho’ (18,1 t $\mathrm{ha}^{-1}$ ). Resende (2000) avaliou cultivares e épocas de colheita quanto à qualidade e produtividade de raízes. Este autor verificou que aos 150 DAP, a cultivar Brazlândia Branca foi $62,7 \%$ mais produtiva (22,8 t ha $\left.{ }^{-1}\right)$ do que a cultivar Brazlândia Roxa (14,3 t ha-1) e aos 200 DAP a cultivar Paulistinha foi a mais produtiva (54,5 t ha-1), sendo a menor produtividade verificada para 'Brazlândia Rosada'. Evidenciam-se assim, diferenças no comportamento produtivo $\mathrm{x}$ idade das cultivares para a colheita.

Na cultura da mandioca, avaliando a produtividade e a qualidade de raízes tuberosas em diferentes épocas de colheita em Lavras (MG), Carvalho et al. (1993) também encontraram diferenças entre cultivares quanto à idade de maior produção de raízes tuberosas, a qual ocorreu aos 16 meses para a cultivar Iracema, aos 20 meses para Mantiqueira e Branca-de-Santa Catarina e aos 22 meses para Sonora, Engana Ladrão e Guaxupé. Segundo esses autores, todas as cultivares apresentaram, aos 20 meses após o plantio, elevada produtividade de raízes tuberosas, com altos teores de massa seca e de amido, ressaltando que tal coincidência é fator desejável, pois se terá maior rendimento agrícola e industrial (farinha e fécula).

Assim, a introdução de cultivares em determinada região deve, segundo Leonel-Neto (1983), ser precedida do conhecimento do seu comportamento diante das condições locais, sobretudo em função da época de colheita, visto que o desconhecimento desse comportamento pode, muitas vezes, levar o produtor a colher seu produto em períodos desfavoráveis.

O objetivo do trabalho foi avaliar as características fisiológicas e de produção de cultivares de batata-doce colhidas em diferentes épocas após o plantio.

\section{MATERIAL E MÉTODOS}

O experimento foi realizado em Mossoró, (5 11' S 37 20، W e 18 m de altitude) sob Argisolo Vermelho-Amarelo. O clima da região pode ser classificado de acordo com Köeppen em BSwh, seco e muito quente, com duas estações climáticas definidas: uma seca (junho a janeiro) e uma chuvosa (fevereiro a maio) (Carmo Filho \& Oliveira, 1989).

O delineamento experimental foi de blocos casualizados completos, em esquema fatorial $3 \times 3$, com quatro repetições. Os tratamentos resultaram da combinação de três cultivares (ESAM 1, ESAM 2 e ESAM 3) e três épocas de colheita (105, 130 e 155 dias após o plantio - DAP).

Segundo relatos de Murilo et al. (1990), a cultivar ESAM 1 apresenta raízes fusiformes com película externa rosada, córtex e polpa branca, que após o cozimento torna-se creme, macia e medianamente seca; a 'ESAM 2' apresenta formato fusiforme alongado com raízes com película externa de colora- ção roxa intensa, córtex e polpa amarela, que mantém a cor mesmo após o cozimento, macia e medianamente seca; e a 'ESAM3' tem raízes em formato fusiforme alongado, película externa roxa, com córtex e polpa amarela, que após cozimento apresenta coloração amarela mais intensa.

O plantio foi realizado em 22/03/ 2000 no espaçamento de $1,0 \times 0,4 \mathrm{~m}$. Foram utilizadas ramas apicais com folhas, colhidas no dia anterior e mantidas à sombra, com oito a dez nós. Em cada cova foram colocadas duas ramas, sendo enterrados de três a quatro nós. As parcelas experimentais foram compostas por três linhas com 2,8 m de comprimento, totalizando $8,4 \mathrm{~m}^{2}$, sendo a área útil representada pela linha central. Todo o experimento foi contornado com bordadura comum aos tratamentos.

No sulco de plantio foram aplicados $20 \mathrm{t} \mathrm{ha}^{-1}$ de esterco bovino, sendo em seguida erguidas leiras com $30 \mathrm{~cm}$ de altura. Foram realizadas capinas manuais obedecendo ao período crítico da cultura (Silva \& Lopes, 1995) e irrigações suplementares, quando necessário.

Nas épocas de colheita, em seis plantas da área útil da parcela experimental, foram determinadas as características fisiológicas: número de folhas por planta; área foliar (medida com o auxílio de um integrador de área LI-COR, modelo LI-3100). As plantas foram colhidas e separadas em raízes não tuberosas ou finas, raízes tuberosas não comercializáveis ou refugo, raízes tuberosas comercializáveis (Silva \& Lopes,1995), lâminas foliares, pecíolos e hastes, para as determinações da massa de matéria seca em estufa de ventilação forçada à temperatura de $70^{\circ} \mathrm{C}$. Posteriormente, calculou-se o tamanho médio das folhas (por meio da relação entre a área foliar e o número de folhas); índice de área foliar (obtida pela relação entre a área foliar e área do terreno ocupada pelas plantas); área foliar específica (obtida pela relação entre a área foliar e a fitomassa seca das folhas); razão de área foliar (obtida pela relação entre a área foliar e a fitomassa seca total das plantas); índice de colheita (obtida pela relação entre a massa de matéria seca das raízes comerciais e a massa de matéria seca total das plantas), pro- 
Tabela 1. Valores médios de tamanho da folha (TF), número de folhas por planta (NFP), área foliar (AF), índice de área foliar (L), área foliar específica (SA), razão de área foliar (FA), índice de colheita (HI) e produtividade primária (PP) em função de cultivares de batata-doce e épocas de colheita (average values of leaf size (TF), number of leaves/plant (NFP), leaf área (AF), leaf área index (L) specific leaf área (AS), leaf área ratio (fa), harvest index (HI) and primary yield (PP) depending on sweet potato cvs. and harvesting time). Mossoró, UFERSA, 2000.

\begin{tabular}{|c|c|c|c|c|c|c|c|c|}
\hline Cultivar & $\begin{array}{c}\mathrm{TF} \\
\left(\mathrm{cm}^{2}\right)\end{array}$ & NFP & $\begin{array}{c}\text { AF } \\
\left(\mathbf{c m}^{2} \text { planta }{ }^{-1}\right)\end{array}$ & $\begin{array}{c}\mathrm{L} \\
\left(\mathrm{m}^{2} \mathrm{~m}^{-2}\right)\end{array}$ & $\begin{array}{c}\text { SA } \\
\left(\mathrm{cm}^{2} \mathbf{g}^{-1}\right)\end{array}$ & $\begin{array}{c}\text { FA } \\
\left(\mathrm{cm}^{2} \mathrm{~g}^{-1}\right)\end{array}$ & $\begin{array}{l}\mathrm{HI} \\
(\%)\end{array}$ & $\begin{array}{c}\text { PP } \\
\left(\mathrm{kg} \mathrm{ha}^{-1}\right)\end{array}$ \\
\hline ESAM 1 & $43,32^{*} a$ & 77,67 a & $3223,90 \mathrm{a}$ & $1,62 \mathrm{a}$ & $269,54 \mathrm{a}$ & $19,92 \mathrm{a}$ & $57,18 \mathrm{a}$ & $8001,00 a$ \\
\hline ESAM 2 & $29,65 \mathrm{c}$ & 108,53 a & 2667,83 a & $1,38 \mathrm{a}$ & 249,18 a & 21,47 a & 49,21 a & 6144,90 a \\
\hline ESAM 3 & $36,32 \mathrm{~b}$ & 92,75 a & 3840,79 a & $1,81 \mathrm{a}$ & 249,54 a & 26,85 a & 49,74 a & $6831,20 \mathrm{a}$ \\
\hline \multicolumn{9}{|c|}{ Épocas de colheita (DAP) } \\
\hline 105 & $30,99 \mathrm{~b}$ & $133,17 \mathrm{a}$ & $3311,56 \mathrm{a}$ & $1,70 \mathrm{a}$ & $256,80 \mathrm{a}$ & 24,73 a & $43,87 \mathrm{~b}$ & $7027,05 a$ \\
\hline 130 & 43,88 a & $85,83 \mathrm{~b}$ & 3767,97 a & $1,88 \mathrm{a}$ & 261,06 a & $28,71 \mathrm{a}$ & $47,95 \mathrm{~b}$ & $6297,70 \mathrm{a}$ \\
\hline 155 & $34,42 \mathrm{~b}$ & $60,00 \mathrm{~b}$ & $2653,00 \mathrm{a}$ & $1,23 \mathrm{a}$ & $250,41 \mathrm{a}$ & $14,80 \mathrm{~b}$ & $64,31 \mathrm{a}$ & $7652,35 a$ \\
\hline DMS & 6,21 & 39,91 & 1956,23 & 0,97 & 22,65 & 7,49 & 9,68 & 1874,5 \\
\hline CV (\%) & 17,04 & 35,32 & 47,03 & 46,98 & 10,79 & 32,19 & 18,60 & 34,33 \\
\hline
\end{tabular}

*Nas colunas, médias seguidas pela mesma letra não diferem significativamente entre si pelo teste de Tukey ao nível de $5 \%$ de probabilidade; $\mathrm{DAP}=$ dias após o plantio (means followed by the same letter in the column did not differ from each other by the Tukey tes, $5 \%$ ).

dutividade primária (fitomassa total por hectare). Também foram determinadas as características produtivas: comprimento e diâmetro da parte mediana das raízes comerciais (utilizando-se régua graduada e paquímetro); número de raízes comerciais por planta, massa unitária das raízes comerciais, produtividade da parte aérea, de raízes comerciais e totais (raízes comerciais + não comerciais).

Os dados obtidos foram submetidos à análise de variância e as médias dos tratamentos comparadas entre si pelo teste de Tukey ao nível de 5\% de probabilidade, sendo utilizado o software SAEG v. 9.0.

\section{RESULTADOS E DISCUSSÃO}

Não foi observada interação significativa para os fatores estudados (cultivar x época de colheita) para as características fisiológicas da planta (Tabela 1). Apenas o tamanho das folhas (TF) variou significativamente entre as cultivares, sendo que a 'ESAM 1' superou a 'ESAM 2' em 13,7 cm² e a 'ESAM 3' em $7,0 \mathrm{~cm}^{2}$. Porém, apesar de não ser significativo, essas diferenças foram compensadas pelo número de folhas por planta (NFP), que variou de, 77,7 a 108,5, não sendo verificada alteração na área foliar (AF) e, conseqüentemente, no índice de área foliar (IAF). Considerando as épocas de colheita, com o aumento do ciclo da planta, geralmente ocorre diminuição da área foliar devido à senescência e abscisão foliar, porém com condições favoráveis ao desenvolvimento vegetativo esta variável pode ser mantida em altos níveis (Figueiredo,1993). Folquer (1978) obteve IAF = 1,8 no final do ciclo, portanto, semelhante aos observados nesse trabalho. Figueiredo (1993), em condições de elevada precipitação e de altas temperaturas, verificou IAF superior a 4,0, aos 168 DAP. Segundo Folquer (1978) o valor de $\operatorname{IAF}=3,0$ na fase de tuberização é considerado ótimo para obtenção de alta produtividade de raízes.

Com relação à área foliar específica (SA), observou-se que a variação do TF entre as cultivares não promoveu sombreamento das folhas da camada inferior, pelo menos em proporção suficiente para alterar significativamente a espessura das mesmas. Aos 155 DAP a fitomassa total (FA) foi menor do que aos 105 e 130 DAP em 40,2\% e 48,4\%, respectivamente. Isso pode ser justificado pelo mais alto índice de colheita (HI) obtido aos 155 DAP (64,3\%) demonstrando que nessa época o dreno metabólico preferencial foram as raízes tuberosas e não a parte aérea. Estes valores foram superiores aos obtidos por outros pesquisadores (Folquer, 1978; Figueiredo, 1993). Nas colheitas realizadas aos 105 e 130 DAP as plantas apresentaram mais assimilados na parte aérea $(\mathrm{HI}=43,9 \%$ e 48,0\%, respectivamente).

Para os componentes de produção, observou-se efeito da interação dos fa- tores (cultivar x época de colheita) apenas para a característica de comprimento de raízes comerciais (CRC), sendo realizado o estudo do desdobramento de cultivares dentro de cada época de colheita (Tabela 2). A cultivar ESAM 3 foi a que apresentou maior CRC nas épocas 105 e 130 DAP, enquanto para a 'ESAM 2', foi observado maior CRC aos 155 DAP, evidenciando que o aumento do ciclo foi benéfico, promovendo maior crescimento de suas raízes. Com relação ao diâmetro das raízes comerciais (DRC), verificou-se que não houve efeito das épocas de colheita; entretanto, observou-se nas cultivares ESAM 1 e ESAM 3 os maiores valores desta variável, superando a 'ESAM 2'.

Verificou-se efeito significativo no número de raízes comerciais por planta (NRCP), apenas para as épocas de colheita, sendo observados maiores valores aos 155 DAP, resultados, concordando com o observado por Resende et al. (1999). Verificou-se que a época de colheita não alterou a massa das raízes comerciais (MRC). Porém observa-se efeito significativo entre as cultivares, sendo que a 'ESAM 3' apresentou 257,0 g por raiz comercial, valor superior à massa das raízes das demais cultivares. Desta forma, as raízes comerciais da 'ESAM 3' podem ser classificadas como Extra A (Silva \& Lopes, 1995), tendo possivelmente melhor aceitação.

A produção de fitomassa (PFM), produtividade de raízes comerciais (PRC) e produtividade total de raízes 
Tabela 2. Valores médios de comprimento das raízes comerciais (CRC), diâmetro das raízes comerciais (DRC), número de raízes comerciais por planta (NRCP), massa das raízes comerciais (MRC), produção de fitomassa (PFM), produtividade de raízes comerciais (PRC) e produtividade total de raízes (PTR) em função de cultivares de batata-doce e épocas de colheita (average values of lenght of commercial roots (CRC), diameter of commercial roots (DRC), number of commercial roots/plant (NRCP), mass of commercial roots (MRC), yield of phytomass (PFM), yield of commercial roots (PRC) and total yield of roots (PTR)). Mossoró, UFERSA, 2000.

\begin{tabular}{|c|c|c|c|c|c|c|c|c|c|}
\hline Cultivares & & CRC $(\mathrm{cm})$ & & $\begin{array}{l}\text { DRC } \\
(\mathrm{cm})\end{array}$ & NRCP & $\begin{array}{c}\text { MRC } \\
(\mathrm{g})\end{array}$ & $\begin{array}{c}\text { PFM } \\
\left(\mathrm{kg} \mathrm{ha}^{-1}\right)\end{array}$ & $\begin{array}{c}\text { PRC } \\
\left(\mathrm{kg} \mathrm{ha}^{-1}\right)\end{array}$ & $\begin{array}{c}\text { PTR } \\
\left(\mathrm{kg} \mathrm{ha}^{-1}\right)\end{array}$ \\
\hline ESAM 1 & & & & $5,14^{*} a$ & $1,44 a$ & $195,44 \mathrm{~b}$ & $14.579,1 \mathrm{a}$ & $13.421,7 \mathrm{a}$ & $16.670,3 \mathrm{a}$ \\
\hline ESAM 2 & & & & $4,59 \mathrm{~b}$ & $1,36 a$ & $174,86 \mathrm{~b}$ & $10.588,5 a$ & $11.602,8 \mathrm{a}$ & $15.925,6 \mathrm{a}$ \\
\hline ESAM 3 & & & & 5,29 a & $1,16 \mathrm{a}$ & 257,03 a & $14.223,7 \mathrm{a}$ & $12.890,8 \mathrm{a}$ & $15.985,8 \mathrm{a}$ \\
\hline \multicolumn{10}{|c|}{ Desdobramento (cultivares $\mathrm{x}$ época de colheita)* } \\
\hline $\begin{array}{l}\text { Épocas de } \\
\text { colheita } \\
\text { (DAP) }\end{array}$ & ESAM 1 & ESAM 2 & ESAM 3 & & & & & & \\
\hline 105 & $14,92 \mathrm{AB}$ & $14,48 \mathrm{~B}$ & $17,62^{*} \mathrm{~A}$ & $4,73 a$ & $0,96 \mathrm{~b}$ & 202,92 a & $15.420,0 \mathrm{a}$ & $9.162,5 \mathrm{~b}$ & $13.959,6 \mathrm{~b}$ \\
\hline 130 & $12,75 \mathrm{~B}$ & $15,16 \mathrm{AB}$ & $16,63 \mathrm{~A}$ & $5,17 a$ & $1,20 b$ & 209,10 a & $15.041,9 \mathrm{a} \mathrm{b}$ & $11.001,9 b$ & $14.020,8 \mathrm{~b}$ \\
\hline 155 & $13,50 \mathrm{~B}$ & $16,40 \mathrm{~A}$ & $13,45 \mathrm{~B}$ & $5,12 \mathrm{a}$ & $1,80 a$ & 215,30 a & $8.929,4 \mathrm{~b}$ & $17.750,8 \mathrm{a}$ & $20.701,6 \mathrm{a}$ \\
\hline DMS & & 2,80 & & 0,50 & 0,49 & 55,22 & 4050,00 & 2349,00 & 850,43 \\
\hline CV (\%) & & 10,59 & & 8,27 & 37,14 & 25,92 & 48,28 & 40,12 & 36,06 \\
\hline
\end{tabular}

*Nas colunas, as médias seguidas pela mesma letra minúscula e nas linhas pela mesma letra maiúscula não diferem significativamente entre si pelo teste de Tukey ao nível de 5 \% de probabilidade; DAP=dias após o plantio (means followed by the same small letters in the line and capital in the column did not differ from each other, Tukey's test, 5\%).

(PTR) não foram influenciadas pelas cultivares. Com relação às épocas de colheita, a PFM foi menor aos 155 DAP devido, provavelmente, à senescência das plantas e à abscisão foliar. Os maiores valores de PTR (20.702 $\mathrm{kg} \mathrm{ha}^{-1}$ ) e PCR (17.751 kg ha-1) foram obtidos aos 155 DAP. As produtividades obtidas foram superiores aos relatos de Murilo et al., (1990) para a colheita com ciclo de 130 DAP. Resultados semelhantes foram encontrados por Resende (2000), que obteve incremento na produtividade de todas as cultivares aos 200 DAP, atribuindo os resultados ao maior período de permanência da cultura no campo. Com relação às outras épocas, não foram verificadas alterações significativas na PFM, PRC e PTR. Dessa forma, o produtor pode antecipar a colheita em 25 dias sem perdas, ou adiá-la por igual tempo com ganhos significativos no rendimento, proporcionando-lhe maior flexibilidade quanto à demanda e preço de mercado. Além disso, também pode utilizar a fitomassa na alimentação animal, com colheitas a partir dos 105 DAP.

\section{REFERÊNCIAS}

CARMO FILHO F; OLIVEIRA OF. 1989. Mossoró: um município do semi-árido nordestino "Características climáticas e aspectos florísticos”. Mossoró: ESAM. 62 p.

CARVALHO VD; CHAGAS SJR; BOTREL N. 1993. Produtividade e qualidade de raízes em diferentes épocas de colheita de variedades de mandioca. Revista Brasileira de Mandioca 12: 49-58.

FIGUEIREDO AF. 1993. Armazenamento de ramas, tipos de estacas, profundidade de plantio e análise do crescimento de batata-doce [Ipomoea batatas (L) Lam.]. Viçosa: UFV. 127p (Tese mestrado).

FOLQUER F. 1978. La batata (camote) estudio de la planta y su producción comercial. San José: IICA, 144 p.

IBGE. Instituto Brasileiro de Geografia e Estatística. 2005, 20 de agosto. Indicadores conjunturais - produção agrícola/agricultura. Disponível em http://www.ibge.gov.br/.

LARCHER W. Physiological plant ecology. 1995. Berlin: Springer. $448 \mathrm{p}$.

LEONEL-NETO M. 1983. Influência da idade de colheita e espaçamento sobre algumas características de duas cultivares de mandioca (Manihot esculenta Crantz). Lavras: UFLA. 57p. (Tese mestrado).

MENEZES MA; SANTOS MA; QUEIROGARCF; SILVA MC; VIEIRA CPG. 2001. Características fisiológicas de cultivares de batata-doce em função da época de colheita. In: CONGRESSO BRASILEIRO DE OLERICULTURA, 41. Resumos... Brasília: SOB (CD-ROM).
MURILO DV; PEDROSA JF; NUNES CLF. 1990. ESAM 1, 2 e 3: Novas cultivares de batata-doce para a região semi-árida. Horticultura Brasileira 8: 32-33.

PEIXOTO N; MIRANDA JEC; FILGUEIRA FAR; CÂMARA FLA. 1989. Avaliação de clones de batata-doce em Goiás. Goiânia: EMGOPA-DDI, 12 p. (Boletim de Pesquisa, 16).

PEREIRA CR; SANTOS MA; RIBEIRO HU; BARRA PB; LOURO FSC; QUEIROGA RCF. 2003. Composição química dos resíduos de cultivares de batata-doce submetida a diferentes idades de colheita. In: CONGRESSO BRASILEIRO DE OLERICULTURA, 43. Resumos... Recife: SOB (CD-ROM).

RESENDE GM. 1999. Características produtivas de cultivares de batata-doce sob condições irrigadas e de sequeiro na região norte de Minas Gerais. Horticultura Brasileira 17: 151154.

RESENDE GM. 2000. Características produtivas de cultivares de batata-doce em duas épocas de colheita, em Porteirinha - MG. Horticultura Brasileira 18: 68-71.

SILVA JBC; LOPES CA. 1995. Cultivo de batata-doce [Ipomoea batatas (L.) Lam.]. Brasília: EMBRAPA-CNPH, 18 p. (Instruções Técnicas - $\mathrm{CNPH}, 7)$.

SMITH WEJM; MANTENGO LO. 1995. Farmer's cultural practices and their effects on pest control in sweet potato in south Nyanza, Kenia. International Journal of Pest Management 41: 2-7. 